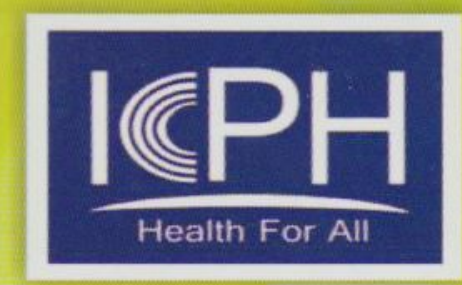

ISBN: 978-602-71484-4-4

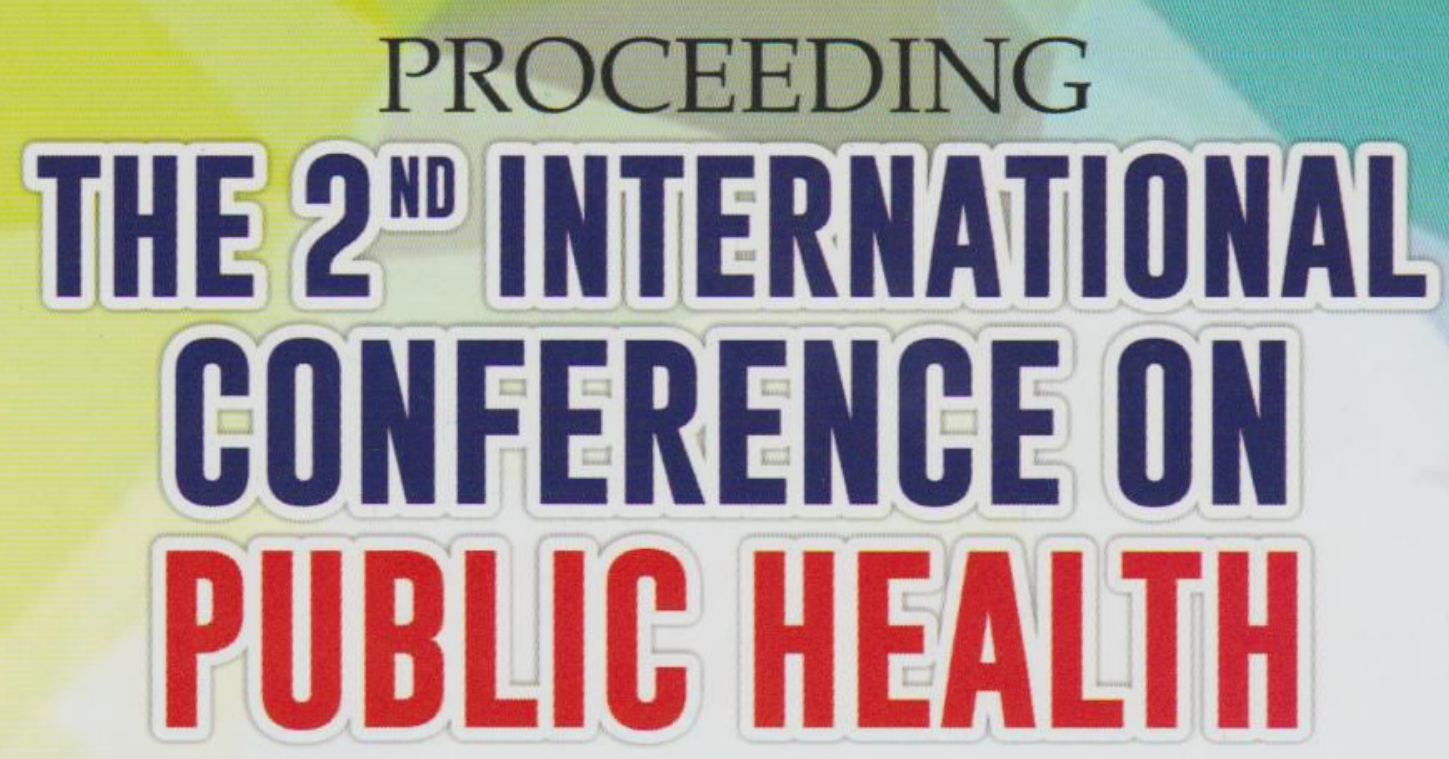

Theme:

"Multisectoral Action to Combat Regional and Social Inequities in Health"

Reviewers:

Prof. Bettina Borisch Prof. Diana Kuh Prof. Malin Eriksson Dr. Robert Chad Swanson Prof. Maria Emmelin Dr. Monika Arora Prof. Wongsa Laohasiriwong Prof. Sanjiv Kumar Prof. Bhisma Murti

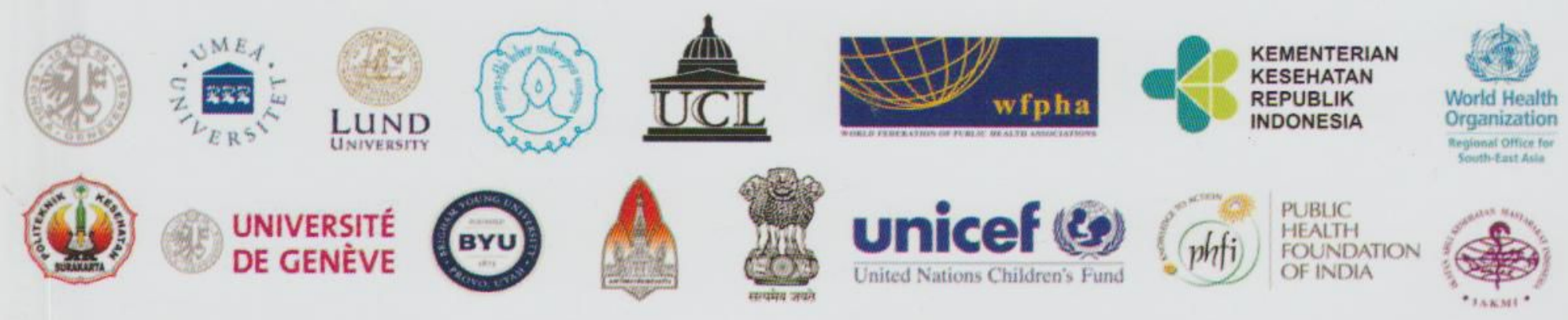




\title{
FACTORS ASSOCLATED WITH SMOKING HABIT AMONG HIGH SCHOOL STUDENTS IN SOE, SOUTH TIMOR TENGAH, EAST NUSA TENGGARA
}

\author{
Yusiany Nenosono, Intje Picauly, Sabina Gero
}

Masters Program in Public Health, Nusa Cendana University, Kupang

\begin{abstract}
3ackground: Many adolescents start smoking at an early age because of riosity and venturesomeness. Early start of smoking makes it difficult to zit smoking. Adolescents' habitual smoking not only becomes an entry point all kinds of substance abuse but also causes various health problems ncluding upper respiratory infection, immature lung development, reduced maximum vital capacity, and lung cancer. The purpose of this study was to amine factors associated with smoking habit in high school students in Soe, south Timor Tengah, East Nusa Tenggara.

Subjects and Method: This was a crosssectional study conducted at 3 unior High Schools in Soe, South Timor Tengah, East Nusa Tenggara. A ample of 107 students was selected for this study by stratified random sampling. The dependent varible was smoking status. The independent ariables were gender and smoking peer group. The data were collected by fuestionnaire and analyzed by logistic regression.

Results: Male students (OR=223.73; CI $95 \%=13.78$ to $3,631.59 ; \mathrm{p}<0.001$ ) and attachment with smoking peer group (OR=33.33; CI $95 \%=3.57$ to $100.00 ; p=0.002)$ were associated with increased risk of smoking among
tigh school students.

Conclusion: Male and attachment with smoking peer group are associated with increased risk of smoking among high school students.
\end{abstract}

Keywords: smoking, adolescent, gender, peer group

Correspondence: Yusiany Nenosono. Masters Program in Public Health, Nusa Cendana University, East Nusa Tenggara. Email:

nenosonoyusiani@gmail.com. Mobile: +6285253134121. 